\title{
Dialectics of nature in materials science: binary cooperative complementary materials
}

\author{
Mingjie Liu ${ }^{1,2}$ and Lei Jiang ${ }^{1,3^{*}}$
}

\begin{abstract}
Binary cooperative complementary materials, consisting of two components with entirely opposite physiochemical properties at the nanoscale, are presented as a novel principle for the design and construct of functional materials. By summarizing recent achievement in materials science, it can be found that the cooperative interaction distance between the pair of complementary property must be comparable with the scale of related physical or chemical parameter. When the binary components are in the cooperative distance, the cooperation between these building blocks becomes dominant and endows the macroscopic materials with unique properties and advanced functionalities that cannot be achieved by either of building blocks.
\end{abstract}

Keywords: dialectics of nature, binary cooperative complementary materials, cooperative interaction distance, material design

The binary cooperative complementary phenomenon, which refers to two entirely opposite but cooperative, complementary states, may be observed at many different levels of nature [1]. For example, we have a positive nucleus and negative electrons at the atomic level, hydrophilicity and oleophilicity in molecules, hard inorganic and soft organic components in biological tissues, male and female in biology, odd and even in mathematics, north and south in magnetism, and matter and anti-matter in the universe [2] (Fig. 1). The law of unity and interpenetration of opposites was proposed in "Dialectics of Nature," an unfinished 1883 work by Friedrich Engels. He stated "Everywhere we look in nature, we see the dynamic co-existence of opposing tendencies. This creative tension is what gives life and motion." [3] Dialectics was derived from the works of philosophers G. W. F. Hegel (1831) and Heraclitus
(500 BC), who thought that everything was constantly changing and that all things consisted of two opposite elements that could change into each other. Ancient Chinese philosophers also utilized "Yin" and "Yang" as two basic polarities of the universe to interpret the binary cooperative complementary phenomenon in nature and the universe. However, Engels simply thought the idea of "Yin" and "Yang" was just an embryo of dialectics in ancient China. However, Chinese philosophers had already studied the evolution process and unity of two opposite elements quantitatively. For example, "I Ching" (1000-750 BC), an ancient Chinese book of changes, stated that 64 Yin-Yang combinations known as "64-gua" are possible with hexagrams (patterns of 6 broken and unbroken lines) [4]. This "64-gua" is remarkably consistent with 64 combined results of DNA genetic codons, which consist of 3 nucleobases from adenine (A), thymine (T), cytosine (C), and guanine $(\mathrm{G})$ in a group and up to $4^{3}$ or 64 amino acids can be encoded. Based on the complementary base pairing principle, genetic codons can be translated into proteins (amino acid sequences) by living cells. An extraordinary Chinese philosopher Laozi (600-400 BC) also pointed out, "Everything is formed by two opposing elements" (Fig. 2). In his Daodejing, he fully illustrated the interplay of "Yin" and "Yang" and proposed the principle of learning from nature, which now plays an important and profound role in modern science. As the essence of Chinese philosophy, "Yin" and "Yang" has already been proved in a wide variety of fields ranging from science and technology to politics and economy in the history of nature and human society.

In the development of materials science, the binary cooperative complementary principle has already been widely

\footnotetext{
${ }^{1}$ Key Laboratory of Bio-Inspired Smart Interfacial Science and Technology of Ministry of Education, School of Chemistry and Environment, Beihang University, Beijing 100191, China

${ }^{2}$ International Research Institute for Multidisciplinary Science, Beihang University, Beijing 100191, China

${ }^{3}$ Laboratory of Bio-inspired Smart Interface Science, Technical Institute of Physics and Chemistry, Chinese Academy of Science, Beijing 100191, China

${ }^{*}$ Corresponding author (email: jianglei@iccas.ac.cn)
} 


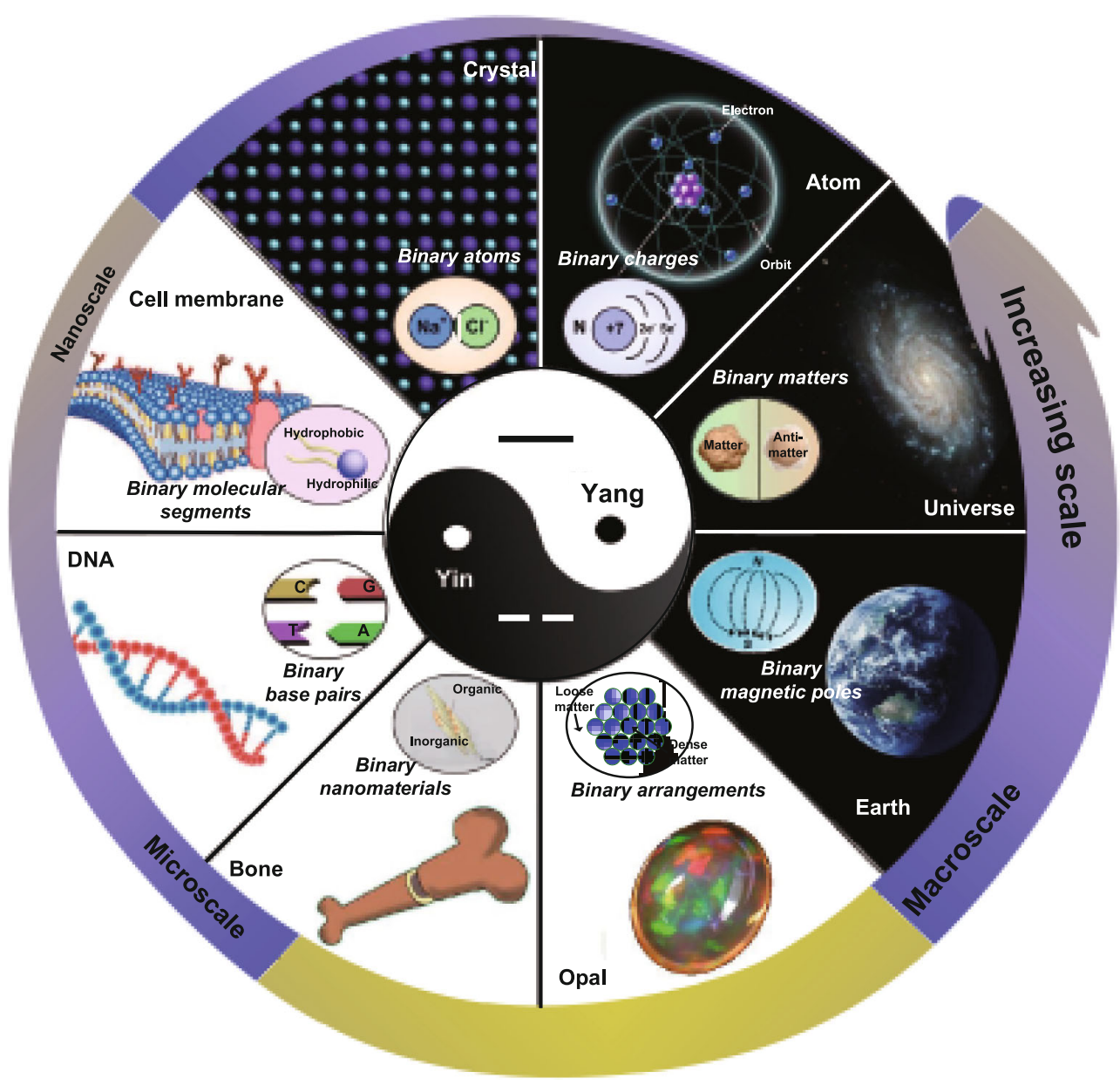

Figure 1 Binary cooperative complementary phenomena may be observed at many different levels of nature. Reprinted with permission from Ref. [2], Copyright 2014, WILEY-VCH Verlag GmbH \& Co. KGaA, Weinheim.

道法自然

Learning from nature

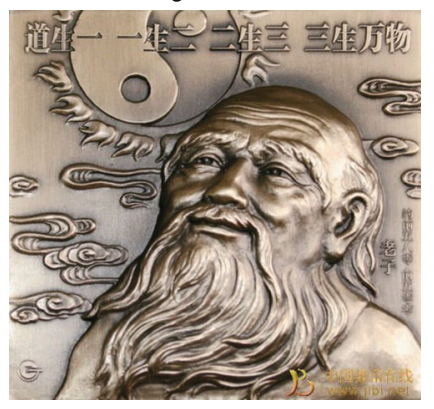

Laozi

$600-400 \mathrm{BC}$
实事求是 Seek law from facts

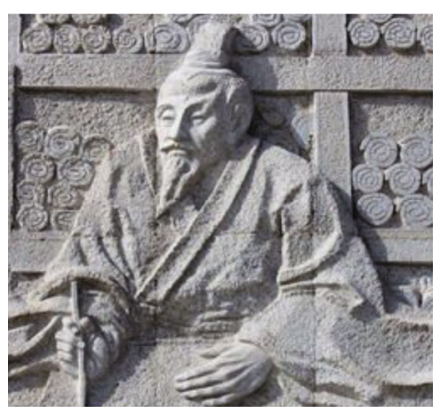

Ban Gu

$32-92 A D$
自然辩证法

Dialectics of nature

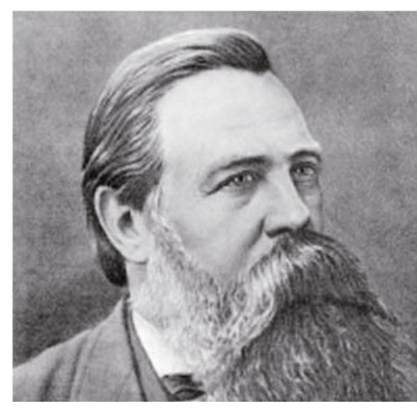

Frederick Engels 1820-1895

Figure 2 Images of ancient Chinese philosopher Laozi, Ban Gu, and German philosopher Frederick Engels.

utilized to design and create novel functional materials. To date, various types of binary atomic materials and binary molecular materials have been successfully developed and have shown tremendous potential in both basic research and practical applications, as shown in Fig. 3. For example, in DNA, two long polymer chains bearing four kinds of 


\begin{tabular}{|c|c|c|}
\hline Types & $\begin{array}{l}\text { Characteristic } \\
\text { physical length }\end{array}$ & Representative application \\
\hline $\begin{array}{l}\text { Base pair distance } \\
\text { (Adeninethynine guanine/(ytosine) }\end{array}$ & ca. $0.3 \mathrm{~nm}$ & elix \\
\hline Length of oleophilic group & $1-2 \mathrm{~nm}$ & 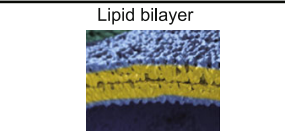 \\
\hline Molecules distance & $<1 \mathrm{~nm}$ & Molecule identification \\
\hline Size of cavity & $0.3-2 \mathrm{~nm}$ & lar sieve \\
\hline Ionic coupling distance & $0.3-1 \mathrm{~nm}$ & \\
\hline $\begin{array}{l}\text { Molecules spacing } \\
\text { (In-plane/out-of-plane) }\end{array}$ & $0.3-1 \mathrm{~nm}$ & $\begin{array}{l}\text { Aggregation-induced } \\
\text { emissive material }\end{array}$ \\
\hline $\begin{array}{l}\text { The Förster raduys } \\
\text { (Donnor/acceptor) }\end{array}$ & $1-10 \mathrm{~nm}$ & Chemical sensors and biosensors \\
\hline
\end{tabular}

Figure 3 Examples of the binary cooperative complementary phenomenon in molecular design.

nucleobases form double-helix structures through hydrogen-bonding interactions between a pair of nucleobases (A to $T$ and $C$ to $G$ ) at a distance of approximately $0.3 \mathrm{~nm}$ [5]. Amphiphilic molecules, also known as surfactants, have both hydrophilic and oleophilic groups in the same molecular structure [6]. They can assemble into a stable lipid bilayer when the length of the oleophilic groups is approximately $1-2 \mathrm{~nm}$. Host molecules combining with guest molecules with an appropriate spacing $(<1 \mathrm{~nm})$ by the intermolecular force have been widely used in molecule identification [7]. A molecular sieve with a cavity size of approximately $0.3-2 \mathrm{~nm}$ can be used to separate different molecules with different sizes [8]. Zwitterionic molecules with both positive and negative groups in the same molecular structure at a distance approximately $0.3-1 \mathrm{~nm}$ (ionic coupling distance) are strongly hydrated through ionic solvation and thus create a strong repulsive force on protein. Such molecules can be used to prepare non-fouling materials $[9,10]$. When the conjugate molecules aggregate at a certain distance $(<1 \mathrm{~nm})$ that restricts intramolecular rotation, the aggregation-induced emission (AIE) phenomenon can be observed $[11,12]$. When a donor molecule in an excited state approaches an acceptor molecule at a distance equal to the Förster radius (1-10 nm), energy transfer may occur through non-radiative dipole-dipole coupling [13]. This energy transfer has been widely used in the design of chemical sensors and biosensors.

The binary cooperative complementary principle has also seen significant success in the field of superwettability. By learning from the natural surfaces with special wettability, we recognized that the cooperative effect of surface micro/nano structures and surface energy is key in superwettability [14-19]. A surface roughness that matches the characteristic length of hydrophobic interaction of $\sim 100 \mathrm{~nm}$ [20] can enhance the hydrophilicity of a substrate with water contact angles (CAs) less than $65^{\circ}$ and enhance the hydrophobicity of a substrate with water CAs greater than $65^{\circ}$ [21]. Following this principle, interfacial materials with extreme wetting states, such as superhydrophobic, superhydrophilic, superoleophobic, and superoleophilic states, can be fabricated from metals, polymers, ceramics, semiconductors, insulator, and so on. By combining micro/nanostructured substrates and responsive molecules, we can also fabricate smart interfacial materials possessing two complementary properties of superwettability that can be switched using light [22-25], $\mathrm{pH}$ [26-31], electric, chemical, or multi-stimuli [32-34]. If the design principle is transferred from an air environment to water or other liquid media, underwater superoleophobic and superareophobic surfaces can be developed [35-42]. Furthermore, novel functional solid/liquid interfacial systems, including three-dimensional integrated materials, two-dimensional membranes, one-dimensional fibers/channels, and zero-dimensional nanoparticles, can be generated and integrated into devices by combining different super-wettability properties $[43,44]$. These systems could be used for oil/water separation, electrochemical catalysis and energy conversion, water collection, control of cell adhesion, and robust surfaces in cosmetics as well as industrial applications [45-52].

In order to gain a deeper understanding of the binary cooperative complementary principle, we present more examples from recent achievements in materials science in Fig. 4. Magnetic/nonmagnetic alternative multilayered nanostructures will lead to remanence enhancement or magnetism-responsive properties. For example, in a magnetic tunnel junction consisting of two ferromagnetic layers isolated by a thin insulator layer (typically a few nanometers in thickness), electrons can be allowed to or prevented from tunneling through the insulating layer by tailoring the orientation of the magnetization, yielding two 


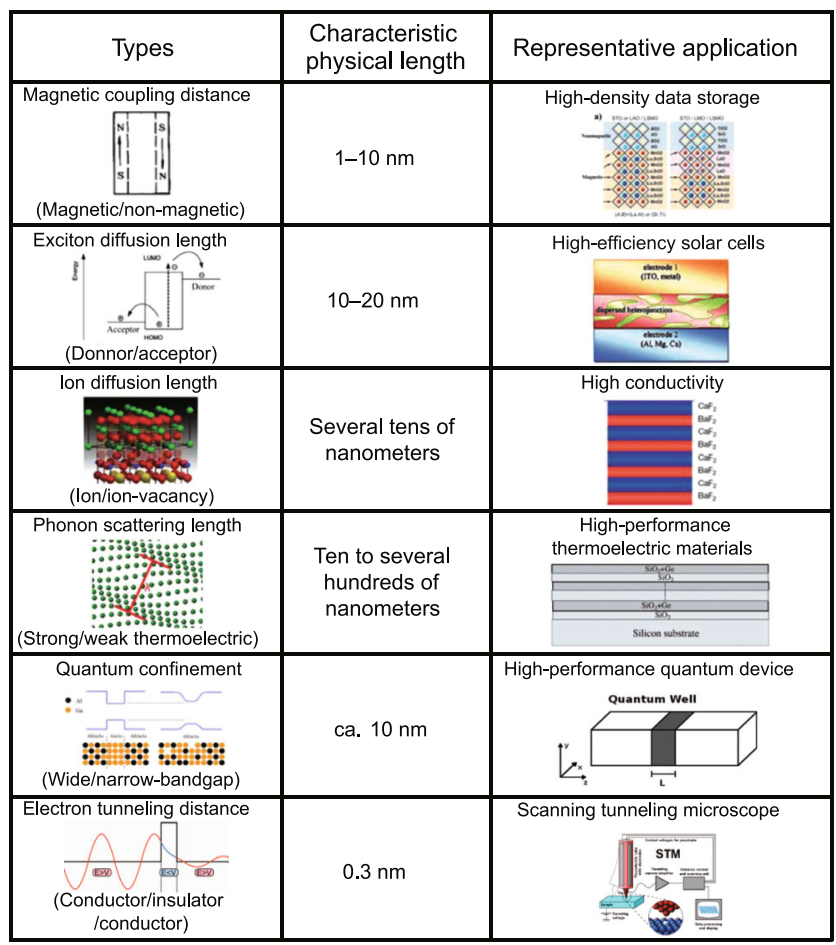

\begin{tabular}{|c|c|c|}
\hline Types & $\begin{array}{l}\text { Characteristic } \\
\text { physical length }\end{array}$ & Representative application \\
\hline $\begin{array}{l}\text { Hydrophil ic interaction } \\
\text { critical distance }\end{array}$ & ca. $100 \mathrm{~nm}$ & Superamphiphilic surface \\
\hline $\begin{array}{l}\text { Hydrophobic interaction } \\
\text { critical distance }\end{array}$ & ca. $100 \mathrm{~nm}$ & Superamphiphobic surface \\
\hline Intermdiate product diffusion & ca. $10 \mathrm{~nm}$ & High-efficiency catalyst system \\
\hline $\begin{array}{l}\text { Minimum thickness of } \\
\text { inorganic crystal sliding }\end{array}$ & ca. $30 \mathrm{~nm}$ & Hard and wear-resistant material \\
\hline $\begin{array}{l}\text { Optical wavelength } \\
\text { in UV-vis-IR range }\end{array}$ & $150-350 \mathrm{~nm}$ & $\begin{array}{l}\text { High photonics focus anti-reflection } \\
\text { का }\end{array}$ \\
\hline $\begin{array}{l}\text { Mean free path of } \\
\text { gas molecules } \\
\text { (Thermal conducting/ } \\
\text { thermal insulating) }\end{array}$ & $20-70 \mathrm{~nm}$ & Heat insulating materials \\
\hline
\end{tabular}

Figure 4 Examples of the binary cooperative complementary phenomenon in materials science.

states of electrical resistance. This mechanism has already been used in the read-heads of modern hard-disk drives [53]. When the electron donors and acceptors are combined at the nanoscale and the distance between the two components is $10-20 \mathrm{~nm}$ (the exciton diffusion length), high-performance photovoltaic devices can be achieved [54]. To facilitate the ion diffusion, nanoscale ion/ion-vacancy binary building blocks need to be assembled with a distance of tens of nanometers, which should match the ion diffusion length in the solid [55,56]. Examples of this type of materials are alternative $\mathrm{CaF}_{2} / \mathrm{BaF}_{2}$ layers [57], $\mathrm{Y}_{2} \mathrm{O}_{3}-\mathrm{ZrO}_{2} / \mathrm{SrTiO}_{3}$ hybrids, and $\mathrm{Ag}_{2} \mathrm{~S}$ nanoparticle- $\mathrm{GeS}_{2}$ mixture [58-60]. Thermoelectric efficiency can be greatly enhanced if strong and weak thermo-electric building blocks hybrid in nanoscale adopt alternative layered structures, in which the thickness of each layer should match the phonon scattering length. Quantum wells (2D) can be fabricated by integrating wide/narrow-bandgap semiconductors, in which the cooperative distance is the average electron free path [61]. A superconducting tunnel junction (Josephson junction) consists of a superconductor and insulator at a distance of $2-5 \mathrm{~nm}$, which is the coupling length of Cooper pairs [62]. Scanning tunneling microscopy and surface-enhanced Raman spectroscopy were designed based on the electron tunneling distance
$(0.3 \mathrm{~nm})$ between conductor/insulator/conductor [63,64]. A high-efficiency catalyst system can be developed if the distance between the oxidized site and reduced site is comparable with the diffusion radius of the intermediate product. Biological tissues, such as teeth and bone, utilize organic/inorganic hybrid nanostructures to enhance their mechanical strength. The minimum thickness of inorganic crystal sliding domains is approximately $30 \mathrm{~nm}$ [65]. Periodically arranged nanoarchitectures of high/low dielectric constant, such as photonic crystals or plasmonic metamaterials, can guide photon directional transport and manipulate light at the nanoscale. In this case, the distance between high/low dielectric building blocks should match the wavelength of light [66]. The aerogel shows high thermal insulation performance if the average pore size is comparable with the mean free path of gas molecules (20-70 nm) [67]. By introducing thermoresponsive segments into the hydrophilic network, nonswellable hydrogel can be prepared [68].

The binary cooperative complementary principle has also been applied to design "multiferroic" materials (Fig. 5). For example, in order to enhance magnetoelectric effects, a promising strategy is to introduce strain coupling between two materials such as a ferromagent and a ferroelectric [69]. When a piezomagnetic (or magnetostrictive) 


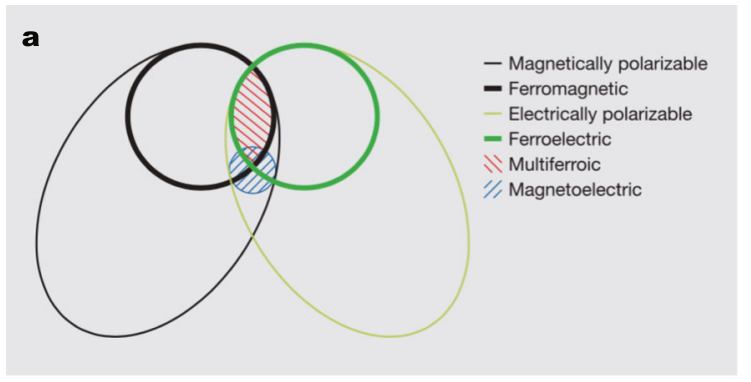

b

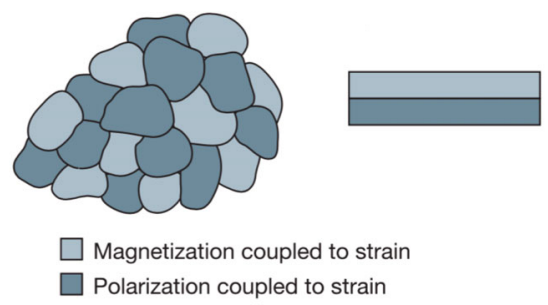

Figure 5 Example of the multiple cooperative complementary effect. (a) The relationship between multiferroic and magnetoelectric materials. (b) Strain-mediated magnetoelectric coupling in two-phase systems. Suitable structures include mixtures of grains and thin-film heterostructures. Reproduced with permission from Ref. [69], Copyright 2006, Nature Publishing Group.

material and piezoelectric (or electrostrictive) material come into intimate contact with each other to form composites, laminates, or epitaxial multilayers, strain coupling can be realized. The coupling constant depends on the frequency of the a.c. applied magnetic field. Such multiferroicstructures could be applied in microwave-frequency transducers.

As the most general laws in the historical development of nature and human society, "Dialectics in nature" can be reduced at a fundamental level to three laws: 1) the law of transformation of quantity into quality and vice versa; 2) the law of interpenetration of opposites; and 3) the law of negation of the negation. Furthermore, by summarizing the recent achievements in materials science, the law of cooperative interaction distance might be considered the fourth law of "Dialectics in nature". The cooperative interaction distance between a pair of complementary properties must be comparable with the scale of related physical or chemical parameters.

In 2000, we extended this principle from the molecular level to the nanostructural level and developed a new material system, i.e., binary cooperative complementary interfacial materials (BCCIMs) [1]. We expected that unique macroscopic functional properties could be generated when two components with entirely opposite properties were introduced at the nanoscale. The design principle and assembly principle of BCCIMs are shown in Fig. 6. These opposite properties could be hydrophilic and oleophilic, oxidizing and reducing, thermally conducting and thermally insulating, ferromagnetic and antiferromagnetic, p-type and n-type, positive swelling and negative swelling, high dielectric constant and low dielectric constant, strong thermoelectric and weak thermoelectric, convex and concave, ion and ion vacancy, electron donor and electron acceptor, and so on. The key parameter for designing BCCIMs is the cooperative distance $\Delta$ between the pair of complementary components. Numerous achievements indicate that the cooperative distance $\Delta$ must be comparable with the scale of the related physical or chemical parameter. When the binary components are separated by the cooperative distance, the cooperation between these building blocks becomes dominant, endowing the macroscopic materials with unique properties and
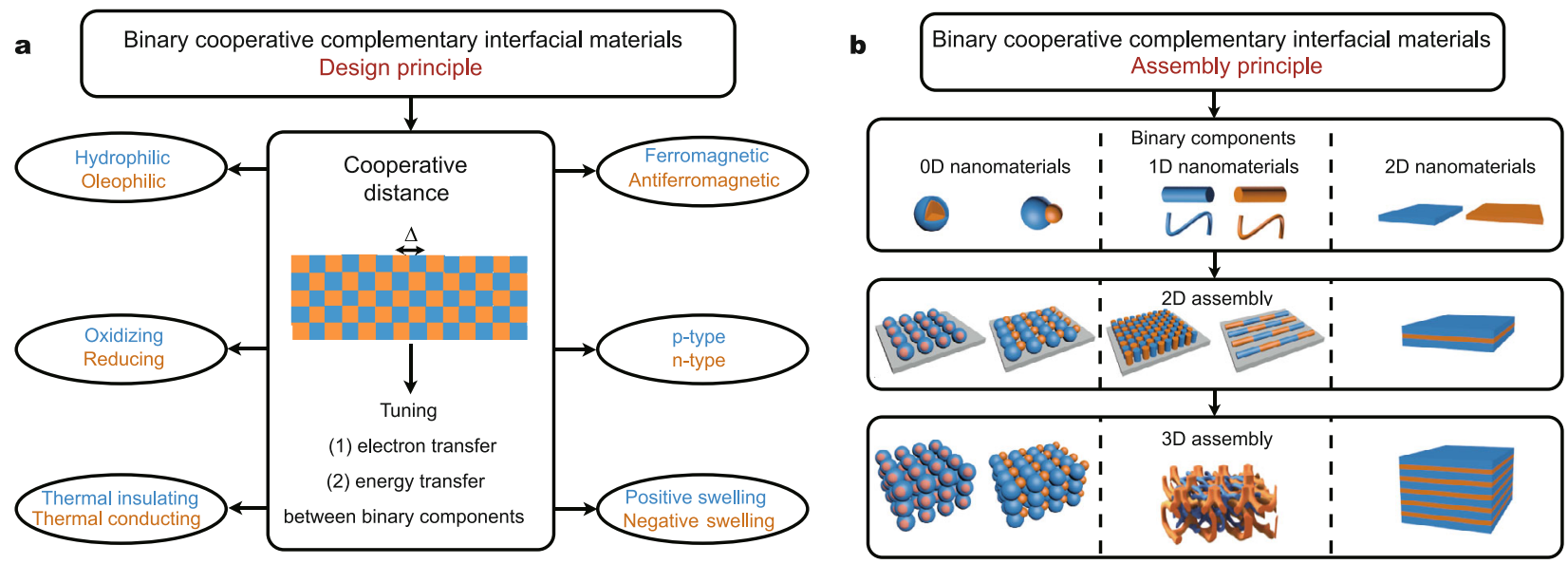

Figure 6 Design principle and assembly principle of binary cooperative complementary interfacial materials. 
advanced functionalities that cannot be achieved individually by either of building blocks. Reversible switching between two entirely opposite macroscopic properties can also be realized on the same interfacial materials. By following the design principle and assembly principle in Fig. 6, we expect that the combination of hydrophilic/oleophilic polymers in 3D cross-linked networks can yield high-performance organohydrogels. Alternative layered structures of thermally conducting/thermally insulating materials can lead to anisotropic thermally insulating materials. A combination of positive-swelling and negative-swelling materials can result in wide-temperature-range non-swelling materials. By sandwiching a photo-conductive organic layer between two inorganic magnetic layers, photo-controlled giant magnetoresistance devices can be fabricated and developed. Considering that so many opposing physical properties exist in the universe, the binary cooperative complementary principle will no doubt lead to the generation of numerous possibilities to construct new functional materials.

\section{Received 13 April 2016; accepted 20 April 2016;} published online 29 April 2016

1 Jiang L, Wang R, Yang B, et al. Binary cooperative complementary nanoscale interfacial materials. Pure Appl Chem, 2000, 72: 73-81

2 Su B, Guo W, Jiang L. Learning from nature: binary cooperative complementary nanomaterials. Small, 2015, 11: 1072-1096

3 Engels F. Dialectics of Nature. Moscow: Foreign Languages Publishing House, 1954, 238-252

4 Schulz LJ.Structural motifs in the arrangement of the 64 gua in the Zhouyi. J Chinese Philos, 1990, 17: 345-358

5 Watson JD, Crick F. A structure for deoxyribose nucleic acid. Nature, 1953, 171: 737-738

6 Rosen MJ, Kunjappu JT. Surfactants and Interfacial Phenomena (4th ed.). Hoboken: Wiley, 2012

7 Hu JJ, Fang M, Cheng YY, Xu TW. Host-guest chemistry of dendrimer-drug complexes. 4. An in-depth look into the binding/encapsulation of guanosine monophosphate by dendrimers. J Phys Chem B, 2010, 114: 7148-7157

8 Davis ME, Lobo RF. Zeolite and molecular sieve synthesis. Chem Mater, 1992, 4: 756-768

9 Chen SF, Jiang SY. A new avenue to nonfouling materials. Adv Mater, 2008, 20: 335-335

10 Jiang SY, Cao ZQ. Ultralow-fouling, functionalizable, and hydrolyzable zwitterionic materials and their derivatives for biological applications. Adv Mater, 2010, 22: 920-932

11 Ding D, Li K, Liu B, et al. Bioprobes based on AIE fluorogens. Acc Chem Res, 2013, 46: 2441-2453

12 Hong YN, Lam JWY, Tang BZ. Aggregation-induced emission: phenomenon, mechanism and applications. Chem Commun, 2009, 29: 4332-4353

13 Medintz IL, Clapp AR, Hedi M, et al. Self-assembled nanoscale biosensors based on quantum dot FRET donors. Nat Mater, 2003, 2: $630-638$

14 Bae WG, Kim HN, Kim D, et al. 25th anniversary article: scalable multiscale patterned structures inspired by nature: the role of hierarchy. Adv Mater, 2014, 26: 675-699

15 Bellanger H, Darmanin T, de Givenchy ET, et al. Chemical and physical pathways for the preparation of superoleophobic surfaces and related wetting theories. Chem Rev, 2014, 114: 2694-2716

16 Liu KS, Yao X, Jiang L. Recent developments in bio-inspired special wettability. Chem Soc Rev, 2010, 39: 3240-3255

17 Liu MJ, Zheng YM, Zhai J, et al. Bioinspired super-antiwetting interfaces with special liquid-solid adhesion. Acc Chem Res, 2010, 43: $368-377$

18 Sato O, Kubo S, Gu ZZ.Structural color films with lotus effects, superhydrophilicity, and tunable stop-bands. Acc Chem Res, 2009, 42: $1-10$

19 Sun TL, Feng L, Gao XF, et al. Bioinspired surfaces with special wettability. Acc Chem Res, 2005, 38: 644-652

20 Lum K, Chandler D, Weeks JD. Hydrophobicity at small and large length scales. J Phys Chem B, 1999, 103: 4570-4577

21 Tian Y, Jiang L. Wetting intrinsically robust hydrophobicity. Nat Mater, 2013, 12: 291-292

22 Feng XJ, Feng L, Jin MH, et al. Reversible super-hydrophobicity to super-hydrophilicity transition of aligned $\mathrm{ZnO}$ nanorod films. J Am Chem Soc, 2004, 126: 62-63

23 Lim HS, Kwak D, Lee DY, et al. UV-driven reversible switching of a roselike vanadium oxide film between superhydrophobicity and superhydrophilicity. J Am Chem Soc, 2007, 129: 4128-4129

24 Rosario R, Gust D, Garcia AA, et al. Lotus effect amplifies light-induced contact angle switching. J Phys Chem B, 2004, 108: $12640-12642$

25 Wang ST, Feng XJ, Yao JN, et al. Controlling wettability and photochromism in a dual-responsive tungsten oxide film. Angew Chem Int Ed, 2006, 45: 1264-1267

26 Heng LP, Tian DL, Chen L, et al. Local photoelectric conversion properties of titanyl-phthalocyanine ( $\mathrm{TiOPc}$ ) coated aligned $\mathrm{ZnO}$ nanorods. Chem Commun, 2010, 46: 1162-1164

27 Krupenkin TN, Taylor JA, Schneider TM, et al. From rolling ball to complete wetting: the dynamic tuning of liquids on nanostructured surfaces. Langmuir, 2004, 20: 3824-3827

28 Tian DL, Chen QW, Nie FQ, et al. Patterned wettability transition by photoelectric cooperative and anisotropic wetting for liquid reprography. Adv Mater, 2009, 21: 3744-3749

29 Tian DL, Zhai J, Song YL, et al. Photoelectric cooperative induced wetting on aligned-nanopore arrays for liquid reprography. Adv Funct Mater, 2011, 21: 4519-4526

30 Wang ST, Liu HL, Liu DS, et al. Enthalpy-driven three-state switching of a superhydrophilic/superhydrophobic surface. Angew Chem Int Ed, 2007, 46: 3915-3917

31 Zhu Y, Li JM, He HY, et al. Reversible wettability switching of polyaniline-coated fabric, triggered by ammonia gas. Macromol Rapid Commun, 2007, 28: 2230-2236

32 Guo Y, Xia F, Xu L, et al. Switchable wettability on cooperative dualresponsive poly-L-lysine surface. Langmuir, 2010, 26: 1024-1028

33 Xia F, Feng L, Wang ST, et al. Dual-responsive surfaces that switch superhydrophilicity and superhydrophobicity. Adv Mater, 2006, 18: $432-432$

34 Xia F, Ge H, Hou Y, et al. Multiresponsive surfaces change between superhydrophilicity and superhydrophobicity. Adv Mater, 2007, 19: 2520-2524

35 Chen X, Wu YC, Su B, et al. Terminating marine methane bubbles by superhydrophobic sponges. Adv Mater, 2012, 24: 5884-5889

36 Gao J, Yao X, Zhao Y, et al. Lyophilic nonwettable surface based on an oil/water/air/solid four-phase system. Small, 2013, 9: 2515-2519 
37 Jarn M, Granqvist B, Lindfors J, et al. A critical evaluation of the binary and ternary solid-oil-water and solid-water-oil interaction. Adv Colloid Interface Sci, 2006, 123-126: 137-149

38 Li YJ, Zhang HC, Xu TH, et al. Under-water superaerophobic pineshaped pt nanoarray electrode for ultrahigh-performance hydrogen evolution. Adv Funct Mater, 2015, 25: 1737-1744

39 Liu MJ, Liu XL, Ding CM, et al. Reversible underwater switching between superoleophobicity and superoleophilicity on conducting polymer nanotube arrays. Soft Matter, 2011, 7: 4163-4165

40 Liu MJ, Wang ST, Wei ZX, et al. Bioinspired design of a superoleophobic and low adhesive water/solid interface. Adv Mater, 2009, 21 665-669

41 Liu MJ, Xue ZX, Liu HL, et al. Surface wetting in liquid-liquid-solid triphase systems: solid-phase-independent transition at the liquidliquid interface by lewis acid-base interactions. Angew Chem Int Ed, 2012, 51: 8348-8351

42 Wang JM, Zheng YM, Nie FQ, et al. Air bubble bursting effect of lotus leaf. Langmuir, 2009, 25: 14129-14134

43 Hanus MJ, Harris AT. Nanotechnology innovations for the construction industry. Prog Mater Sci, 2013, 58: 1056-1102

44 Roduner E. Size matters: why nanomaterials are different. Chem Soc Rev, 2006, 35: 583-592

45 Bai H, Tian XL, Zheng YM, et al. Direction controlled driving of tiny water drops on bioinspired artificial spider silks. Adv Mater, 2010 22: 5521-5525

46 Brown PS, Atkinson ODLA, Badyal JPS. Ultrafast oleophobic-hydrophilic switching surfaces for antifogging, self-cleaning, and oil water separation. ACS Appl Mater Inter, 2014, 6: 7504-7511

47 Callow JA. Callow ME. Trends in the development of environmentally friendly fouling-resistant marine coatings. Nat Commun, 2011, 2: 244

48 Howarter JA, Youngblood JP. Self-cleaning and anti-fog surfaces via stimuli-responsive polymer brushes. Adv Mater, 2007, 19: 3838-3843

49 Kirsch J, Siltanen C, Zhou Q, et al. Biosensor technology: recent advances in threat agent detection and medicine. Chem Soc Rev, 2013, 42: 8733-8768

50 Wang B, Liang WX, Guo ZG, et al. Biomimetic super-lyophobic and super-lyophilic materials applied for oil/water separation: a new strategy beyond nature. Chem Soc Rev, 2015, 44: 336-361

51 Xu ZG, Zhao Y, Wang HX, et al. A superamphiphobic coating with an ammonia-triggered transition to superhydrophilic and superoleophobic for oil-water separation. Angew Chem Inte Ed, 2015, 54: 4527-4530

52 Yuan JK, Liu XG, Akbulut O, et al. Superwetting nanowire membranes for selective absorption. Nat Nanotechnol, 2008, 3: 332-336

53 Giri S, Patra M, Majumdar S. Exchange bias effect in alloys and compounds. J Phys Condens Matter, 2011, 23: 73201-73223

54 Yu G, Gao J, Hummelen JC, et al. Polymer photovoltaic cells: enhanced efficiencies via a network of internal donor-acceptor heterojunctions. Science, 1995, 270: 1789-1791

55 Bueno PR, Leite ER. Nanostructured Li ion insertion electrodes. 1.
Discussion on fast transport and short path for ion diffusion. J Phys Chem B, 2003, 107: 8868-8877

56 Park M, Zhang XC, Chung M, et al. A review of conduction phenomena in Li-ion batteries. J Power Sources, 2010, 195: 7904-7929

57 Sata N, Eberman K, Eberl K, et al. Mesoscopic fast ion conduction in nanometre-scale planar heterostructures. Nature, 2000, 408: 946-949

58 Garcia-Barriocanal J, Bruno FY, Rivera-Calzada A, et al. "Charge leakage" at $\mathrm{LaMnO}_{3} / \mathrm{SrTiO}_{3}$ interfaces. Adv Mater, 2010, 22: 627-632

59 Garcia-Barriocanal J, Rivera-Calzada A, Varela M, et al. Colossal ionic conductivity at interfaces of epitaxial $\mathrm{ZrO}_{2}: \mathrm{Y}_{2} \mathrm{O}_{3} / \mathrm{SrTiO}_{3}$ heterostructures. Science, 2008, 321: 676-680

60 Wang RY, Tangirala R, Raoux S, et al. Ionic and electronic transport in $\mathrm{Ag}_{2} \mathrm{~S}$ nanocrystal-GeS 2 matrix composites with size-controlled $\mathrm{Ag}_{2} \mathrm{~S}$ nanocrystals. Adv Mater, 2012, 24: 99-103

61 Yu-Hsuan K, Kyu LY, Yangsi G, et al. Strong quantum-confined Stark effect in germanium quantum-well structures on silicon. Nature, 2005, 437: 1334-1336

62 Alloul H.Introduction to Superconductivity. In: Introduction to the Physics of Electrons in Solids. Heidelberg: ISpringer, 2011, 1048-1336

63 Pettinger B, Picardi G, Schuster R, et al. Surface-enhanced and STMtip-enhanced Raman spectroscopy at metal surfaces. Single Mol, 2002, 3: 285-294

64 Savage K, Hawkeye M, Esteban R, et al. Revealing the quantum regime intunnelling plasmonics. Nature, 2012, 491: 574-577

65 Gao HJ, Ji BH, Jager IL, et al. Materials become insensitive to flaws at nanoscale: lessons from nature. Proc Natl Acad Sci USA, 2003, 100: 5597-5600

66 Staude I, Decker M, Ventura MJ, et al. Hybrid high-resolution threedimensional nanofabrication for metamaterials and nanoplasmonics. Adv Mater, 2013, 25: 1260-1264

67 Hrubesh LW. Aerogel applications. J Non-cryst Solids, 1998, 225 335-342

68 Kamata H, Akagi Y, Kayasuga-Kariya Y, et al. "Nonswellable" hydrogel without mechanical hysteresis. Science, 2014, 343: 873-875

69 Eerenstein W, Mathur ND, Scott JF. Multiferroic and magnetoelectric materials. Nature, 2006, 442: 759-765

Acknowledgments This research was supported by the National Natural Science Foundation (21574004 and 21421061), National Research Fund for Fundamental Key Projects (2013CB933000, 2012CB933800, 2012CB934100, and 2014CB932203), the Key Research Program of the Chinese Academy of Sciences (KJZD-EW-M01, and KJZD-EW-M03), and the 111 project (B14009).

Author contributions Jiang L proposed the concept of Binary cooperative complementary materials. Liu M and Jiang L wrote the paper and contributed to the general discussion.

Conflict of interest The authors declare that they have no conflict of interest. 


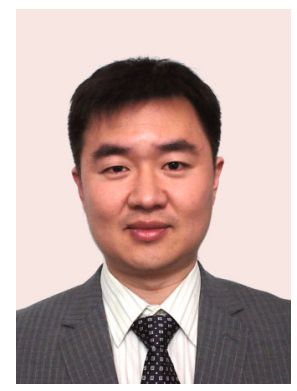

Mingjie Liu is a professor at Beihang University. He received his BSc degree in applied chemistry (2005) from Beijing University of Chemical Technology. In 2005, he joined Prof. Lei Jiang's group and received PhD degree from the National Center for Nanoscience and Technology, Chinese Academy of Sciences (CAS) in 2010. He then worked as a postdoctor in Prof. Takuzo Aida's group in Riken in Japan from 2010 to 2015. In 2015, he got the "1000 Youth Plan Program" and joined Beihang University. His current research interests focus on hydrogel/organogel surfaces with super-wettability, bio-inspired hydrogels with special mechanical strength, anisotropic soft matter with aligned structures.

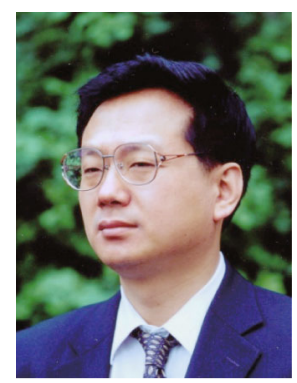

Lei Jiang received his BSc degree in solid state physics (1987), and MSc degree in physical chemistry (1990) from Jilin University in China. From 1992 to 1994, he studied at the University of Tokyo in Japan as a China-Japan joint course PhD student and received his $\mathrm{PhD}$ degree from Jilin University of China with Prof. Tiejin Li. Then, he worked as a postdoctoral fellow in Prof. Akira Fujishima's group at the University of Tokyo. In 1996, he worked as researcher in Kanagawa Academy of Sciences and Technology, Prof. Hashimoto's project. In 1999, he joined the Institute of Chemistry, CAS. In 2015, he moved to the Technoligical Institute of Physics and Chemistry, CAS. Since 2008, he also served as the dean of School of Chemistry and Environment in Beihang University. He was elected as members of the Chinese Academy of Sciences and The World Academy of Sciences in 2009 and 2012. In 2016, he was also elected as a foreign member of the US National Academy of Engineering. His research is focused on bioinspired, smart, multi-scale surfaces with super-wettability and his publications have been cited more than 36000 times with an H-index of 89.

\section{材料科学中的自然辩证法: 二元协同材料}

刘明㷊 ${ }^{1,2}$, 江雷 $1,3^{*}$

摘要 “二元协同材料” 这一新概念, 不同于传统的单一体相材料, 是在材料的宏观表面或体相内建造二元协同纳米界面结构. 该材料设 计原理是, 在介观尺度引入不同甚至完全相反理化性质的纳米微区, 在某种条件下具有协同的相互作用, 以致在宏观上呈现出超常规物性 的材料. 这一新原理的关键是找出这两种组分间的协同距离, 该协同距离应该与物理或化学中的某一特征常数相关. 这一设计原理可以拓 展到材料科学的多个领域, 用于指导制备各种新型功能材料. 